\title{
Research on Decorative and Integrated Thermal Insulation Board for External Wall
}

\author{
Zhang Zhanhua ${ }^{1, \mathrm{~b}}$, II jie ${ }^{1, \mathrm{a}}$, Shi Changyu ${ }^{2, \mathrm{c}}$, Zhang $\mathrm{Chao}^{3, \mathrm{~d}}$, Wang An ${ }^{1, \mathrm{e}}$, Zhang Shan ${ }^{1, \mathrm{f}}$ \\ ${ }^{1}$ Shandong Quality Inspection and Testing Center of Construction Engineering Co., Ltd, Tianqiao District, Jinan City, Shandong Province, \\ China \\ ${ }^{2}$ Heze Municipal Engineering design Institute, Mudan District, Heze City, Shandong Province, China \\ ${ }^{3}$ The Second Construction Limited Company of China Construction eighth engineering, DivisionLixia, District, Jinan City, Shandong \\ Province, China
}

\begin{abstract}
With the acceleration of globalization, industrialization and informatization, the consumption of energy resources is increasing, and the building energy consumption accounts for about $30 \%$, so the building energy conservation has become an important part of energy conservation and emission reduction. At the same time of economic development, we should reduce building energy consumption and do a good job in building energy conservation ${ }^{11]}$, and put forward the following ways: the improvement of building's own heat preservation and insulation performance; the improvement of energy utilization system efficiency such as electricity and heating; the development and utilization of new energy; and the proper management of energy utilization equipment system. Among them, the most effective way is to improve the thermal insulation performance of the building itself. The thermal insulation of enclosure and the air tightness of doors and windows are two important parts of thermal insulation. According to the relevant data ${ }^{[2]}$, the heat loss of enclosure structure accounts for $40-50 \%$ of the building energy consumption, and the heat loss of wall structure accounts for about $70 \%$. Therefore, the improvement of the thermal insulation requirements of the wall structure plays a huge role in building energy conservation

In this paper, the experimental research on the exterior wall thermal insulation board of decoration and heat preservation integration is carried out. The influence of fly ash content, asbestos fiber content, composite active activator, waterproof agent and other additives on the physical properties of fiber-reinforced fly ash / cement board is discussed. The optimal content of various factors is determined and its mechanism is analyzed. The optimum proportion of fiber reinforced fly ash / cement board was determined by orthogonal test.
\end{abstract}

\section{Research Status in China and Research Mechanism of This Project}

Many scholars have studied and discussed the external insulation technology. For example, the performance of external insulation system in winter climate conditions is studied by Zhu Yanfang [3]. The experimental results show that in hot summer and warm winter, hot summer and cold winter and cold winter areas, the applicability of external insulation system in winter is relatively good, and the energy saving effect is more than $40 \%$. Li Xiangzhou ${ }^{[4]}$ not only analyzes the advantages of external and internal insulation of external walls, but also expounds the main external insulation materials and technologies in China, and puts forward several technical problems of external insulation.

The integrated external wall thermal insulation board includes three parts: decoration layer, thermal insulation layer and base plate. Decorative layer materials emphasize decorative effect. Fluorocarbon paint is selected. The polystyrene foam board is used in the insulation layer. The basic level panel has characteristics of small density, high strength, good crack resistance, good impact resistance, good fire resistance and excellent waterproof performance. In view of this requirement, this paper takes fly ash, cement and quartz sand as the main raw materials. The admixture is mainly made of self-made composite. The fiber-reinforced fly ash / cement board is made of active activator, water-proof agent and the base panel. The decoration and heat preservation integrated external wall is made by certain composite technology.

\section{Experimental Materials and Instruments}

\subsection{Experimental Materials}

The main materials include the following types of materials: (1) calcareous raw materials (including 
quicklime and cement); (2) siliceous materials (including fly ash and quartz sand) (3) fiber reinforced materials (including asbestos fiber, whose diameter $3 \sim 9 \mu \mathrm{m}$, fiber length 5 15mm); (4) insulation materials (including polystyrene foam plastic) (5) Fluorocarbon Coatings (including fluorocarbon coating to be UV fluorocarbon anticorrosive coating, it is a two-component coating composed of fluorocarbon resin, special pigments and fillers, solvents, additives and curing agents. (6) Other materials (including resistant structural adhesive, composite active activator, waterproof agent, water reducer and experimental water).

\subsection{Instruments}

(1) X-ray diffractometer(specification DLMX-2550); (2) scanning electron microscope(specification S-2500) (3) electric constant temperature blast drying oven (specification 101-3S); (4) hydraulic universal pressure testing machine(specification YE-300; (5) electric mixer(specification JJ-1); (6) universal testing machine( specification WDW-30); (7) reaction kettle(specification KCF-10; (8) dry ball mill; (9) electronic balance(range $0 \sim 2000 \mathrm{~g}$, accuracy $0.01 \mathrm{~g}$ ); (10) rubber mixer.

\section{Load Test Research after Reinforcement}

\subsection{Raw Material Mix Proportion of Fly Ash / Cement Calcium Silicate Board}

Through comprehensive analysis, the mix proportion design of fly ash / cement calcium silicate board is shown in Table 1.

Table 1 Design Mix Proportion of Fly Ash / Cement Calcium Silicate Composite Board /\%

\begin{tabular}{c|c|c|c|c|c}
\hline Fly ash & Quick lime & cement & Quartz flour & Activator & Water / material ratio \\
\hline 50 & 6.25 & 37.5 & 6.25 & 5 & 0.82 \\
\hline
\end{tabular}

\subsection{Steam Curing System}

The autoclave system of fly ash / cement calcium silicate board is as follows: (1) Stop it before steaming (Drying temperature is $50^{\circ} \mathrm{C}$.Drying time is 4 hours); (2) Heating stage (Heating time is 3 hours); (3) Constant temperature stage (Autoclave temperature is $175^{\circ} \mathrm{C}$. Constant temperature time is 8 hours) (4) Cooling stage (Cooling time is 3 hours).

\subsection{Effect of Asbestos Fiber on Properties of Calcium Board}

In this experiment, the effect of asbestos fiber on the flexural strength of calcium silicate board was investigated. Fixed water material ratio, fly ash, quicklime, cement, quartz powder and activator dosage were used. The dosage of asbestos fiber was set as $2.5 \%$, $5.0 \%, 7.5 \%, 10.0 \%, 12.5 \%, 15.0 \%$ respectively. The relationship between content of asbestos fiber and flexural strength of calcium silicate board is shown in Figure 1.

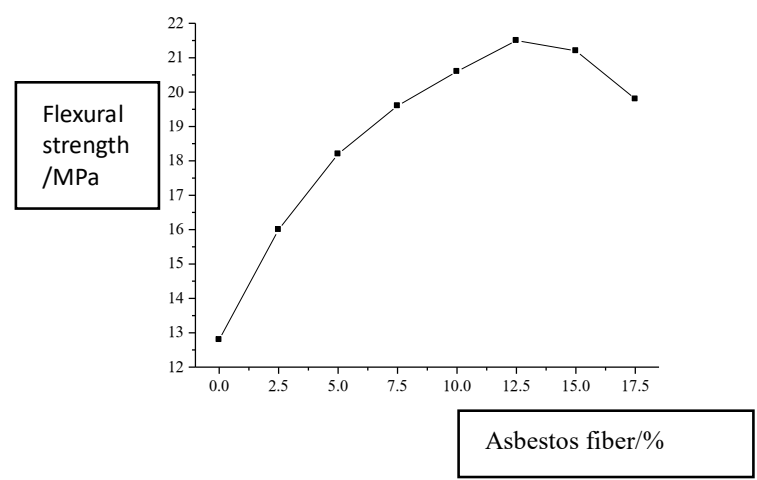

Figure 1 Effect of Asbestos Fiber Content on Flexural Strength of Calcium Silicate Board
It can be seen from Figure 1 that with the increase of the amount of asbestos fiber, the flexural strength of calcium silicate board increases gradually. When the proportion of asbestos fiber is $12.5 \%$, the flexural strength reaches maximum value. When the proportion of asbestos fiber is more than $12.5 \%$, the flexural strength decreases gradually.

\subsection{Effect of Waterproof Agent on Properties of Calcium board}

During the test, the fixed water material ratio, fly ash, quicklime, cement, quartz powder, activator and asbestos fiber dosage are used. The dosage of composite waterproof agent is set as $1 \%, 2 \%, 3 \%, 4 \%, 5 \%$, as shown in table 2 . 
table 2 the Influence of Composite Waterproof Agent on the Water Absorption of Calcium Silicate Board

\begin{tabular}{ccc}
\hline Test Number & Compound Waterproof Agent /\% & Water Absorption Rate /\% \\
\hline $1 \#$ & 0 & 45.8 \\
$2 \#$ & 1 & 36.5 \\
$3 \#$ & 2 & 30.8 \\
$4 \#$ & 3 & 27.2 \\
$5 \#$ & 4 & 25.0 \\
$6 \#$ & 5 & 24.0 \\
\hline
\end{tabular}

It can be seen from table 2 that the water absorption rate of the sample is $45.8 \%$ when no waterproof agent is added. With the increase of waterproof dosage, the water absorption rate of the sample decreases gradually. In this test, it is determined that the content of stearic acid polyvinyl alcohol composite waterproof agent is $4 \%$, at this time, the water absorption rate of the sample is $25.0 \%$, is $47.6 \%$ lower than the blank sample.

The waterproofing mechanism of stearic emulsion can be explained by the theory of interfacial chemical wetting. According to the following formula: $\Delta p=\frac{-2 \gamma_{L G} \cdot \cos \theta}{r}$

Formula: $\Delta \mathrm{P}$ is the additional pressure; $\gamma \mathrm{LG}$ is the surface tension of the liquid; $\theta$ is the contact angle; $\mathrm{R}$ is the radius of the pores.

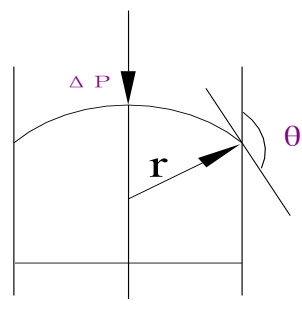

(a)

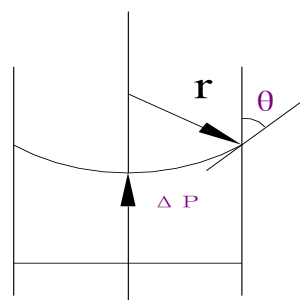

(b)
Figure 2 the Status of the Pores of Liquid Products in Process

When $\theta>90^{\circ}, \Delta \mathrm{P}>0$, the external pressure is greater than $\Delta \mathrm{P}$. The liquid can enter the capillary. When $\theta<90^{\circ}, \Delta \mathrm{P}<0$, the water can automatically penetrate into the pores, as shown in Figure 2 (b). The stearic acid particles emulsified into micron level will be evenly distributed on the surface of fly ash, cement and other powder particles. The stearic acid melted by stearic acid particles will adhere to the surface of the internal pores and pores of the material body, making it change from hydrophilicity to hydrophobicity. The contact angle between the internal pores and the surface of the pores is greater than $90^{\circ}$. When the content of composite waterproof agent is $4 \%$, the waterproof performance of fly ash / cement calcium silicate composite board can better meet the practical application requirements.

\subsection{Mechanism Discussion}

The hardening of fly ash / cement calcium silicate board can be divided into two stages. (1) hydration reaction stage. Under normal pressure, cement and lime react with water form hydrated calcium silicate, hydrated calcium aluminate and $\mathrm{Ca}(\mathrm{OH}) 2$ hydrate. (2) hydrothermal reaction stage. Under high temperature and pressure, the calcium material in the green body reacts with the silicon material form calcium silicate crystal with enough strength.

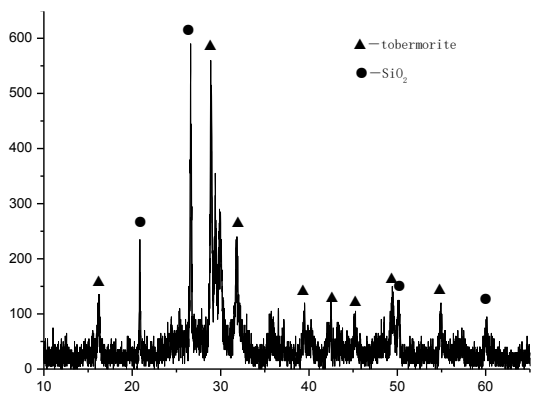

Figure 3 XRD Pattern of Fly Ash / Cement Calcium Silicate Board

XRD spectrum of fly ash / cement calcium silicate board is tested by XRD. The test results are shown in Figure 3. According to the XRD test results, the phase composition of fly ash / cement calcium silicate board is a large amount of tobermory and silica. The target product is synthesized by the raw material ratio and production processing in this project. Unreacted fly ash exists in products as hard fine aggregate is beneficial to improve the hardness and impact resistance of products.
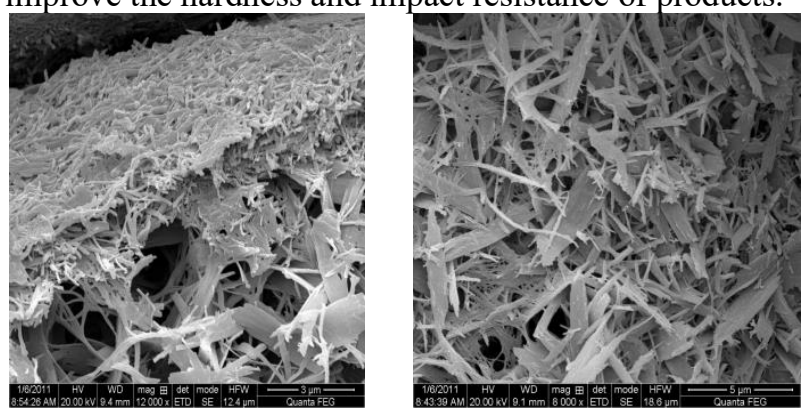

Figure 4 Micro Morphology of Fly Ash / Cement Calcium Silicate Board

The micro morphology of fly ash / cement calcium silicate board is shown in Figure 4. According to the diagram, a large amount of leaf like and needle like mullite is cemented together with $\mathrm{C}-\mathrm{S}-\mathrm{H}$ poor gels and poor crystallinity. There is $3 \sim 5 \mathrm{um}$ being the main form of $3 \sim 5$ um mullite in leaf shape and needle shape. The existence of tobermory not only has non combustibility, but also ensures the strength and excellent high temperature resistance of the products. 


\subsection{Performance test of Fly ash / Cement Calcium Silicate Board}

There are the raw material mix proportion including $0 \%$ fly ash, $37.5 \%$ cement, $6.25 \%$ quicklime, $6.25 \%$ quartz powder, $5 \%$ activator, $12.5 \%$ asbestos fiber, $4 \%$ waterproof agent, and 0.82 water material ratio. The curing shall be carried out according to the following steam curing system. After the sample is dried, They are comprehensively tested including density, flexural strength, water absorption, impact resistance and other properties, according to fiber reinforced calcium silicate board JC / T564-2000 ${ }^{[5]}$. The products are tested by the national building materials testing center, whose results as shown in table 3 .

Table 3 Performance Test Results of Fly Ash / Cement Calcium Silicate Board

\begin{tabular}{ccccc}
\hline $\begin{array}{c}\text { Serial } \\
\text { number }\end{array}$ & Inspection items & $\begin{array}{c}\text { D1.3 Standard index (plate } \\
\text { thickness } 12 \mathrm{~mm})\end{array}$ & Test value & $\begin{array}{c}\text { Single } \\
\text { judgement }\end{array}$ \\
\hline 1 & Density, $\mathrm{g} / \mathrm{cm}^{3}$ & $1.20<\mathrm{D} \leq 1.40$ & 1.25 & qualified \\
2 & flexural strength, $\mathrm{MPa}$ & $\geq 9$ & 11.0 & qualified \\
3 & moisture content, $\%$ & $\leq 10$ & 4.4 & qualified \\
4 & wet expansion rate, $\%$ & $\leq 0.25$ & 0.17 & qualified \\
5 & screw pull-out strength, $\mathrm{N} / \mathrm{mm}$ & $\geq 80$ & 118 & qualified \\
\hline
\end{tabular}

It can be seen from the performance test results that the fly ash / cement calcium silicate board has characteristics of light weight and high strength. Its performance meets or exceeds the requirements of relevant national standards. It can be used as the surface material of decorative panels and light wallboards, can be seen as Figure 5.

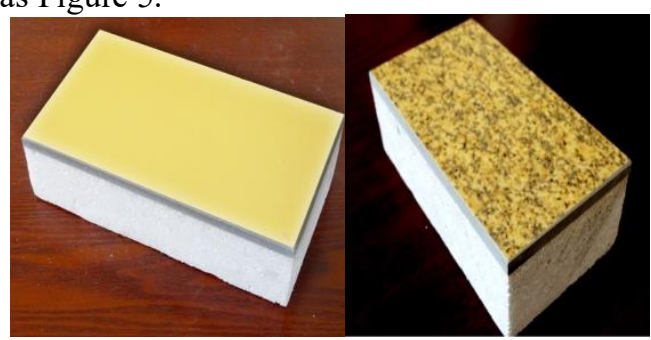

figure 5 Sample Drawing of External Insulation Board of Decoration and Insulation Integration

\section{Summary}

In this paper, the decoration and heat preservation integrated external wall insulation board is studied, and the influence of the following materials on the physical properties of fiber-reinforced fly ash / cement board is studied: fly ash content, asbestos fiber content, composite active activator, waterproof agent, etc. according to the above methods, the best content of each single factor is determined, and its mechanism is analyzed. The optimum proportion of fiber reinforced fly ash / cement board was determined by orthogonal test. According to Fiber Reinforced Calcium Silicate Board, JC/T564-2000 ${ }^{[5]}$, its strength, bonding performance, impact resistance and other properties are tested, so that it can meet the tight combination with insulation layer and decoration layer. It is believed that this kind of external wall insulation board can play a good role in heat preservation and energy saving, and will have a good market and prospect.

\section{Acknowledgement}

In the process of writing this paper, Professor $\mathrm{Li}$ Guozhong put forward valuable opinions and suggestions, for which the author expressed sincere thanks. Thank you very much for Li Jie's help and support. I would like to express my heartfelt thanks to all my colleagues in the laboratory.

\section{References}

1. Report on the Status and Development of China Building Energy Efficiency), [J], China Building Energy Conservation Commission, (2012)

2. Ma Changbo, Lin Jianhao: submitted to FLY ASH COMPREHENSIVE UTILIZATION FENMEIHUI LIYONG (2)2010: p. 39-41.

3. Zhu Yanfang: submitted to Thermal Insulations \& Energy-Saving Technology (04)2003: p.47-49

4. Li Xiangzhou: submitted to Brick-Tile (10) 2005: p. $54-56$

5. Fiber Reinforced Calcium Silicate Board, JC/T564-2000, Beijing, National Bureau of building materials 